\title{
Polyethylene glycol dimethyl ether (PEGDME)-based electrolyte for lithium metal battery
}

Lorenzo Carbone ${ }^{1}$, Mallory Gobet ${ }^{2}$, Jing Peng ${ }^{2,3}$, Matthew Devany ${ }^{4}$, Bruno Scrosati $^{5}$, Steve Greenbaum $^{2, *}$ and Jusef Hassoun ${ }^{1 *}$

${ }^{1}$ Sapienza University of Rome, Chemistry Department, Piazzale Aldo Moro, 5, 00185, Rome, Italy

${ }^{2}$ Department of Physics \& Astronomy, Hunter College of the City University of New York, New York, New York 10065, United States ${ }^{3}$ Ph.D. Program in Chemistry, City University of New York, New York, NY 10016 United States

${ }^{4}$ Department of Chemistry and Biochemistry, Hunter College of the City University of New York, New York, New York 10065, United States

${ }^{5}$ Electtrochimica ed Energia, Rome, Italy (Presently at the Helmholtz Institute, Ulm, Germany)

Corresponding authors: jusef.hassoun@uniroma1.it; steve.greenbaum@hunter.cuny.edu

Keywords: Polyethylene glycol dimethyl ether; electrolyte; lithium battery; NMR; safety

\begin{abstract}
We propose in this work a polyethylene glycol dimethyl ether (MW 500) dissolving lithium trifluoromethansulfonate $\left(\mathrm{LiCF}_{3} \mathrm{SO}_{3}\right)$ salt as suitable electrolyte media for a safe and efficient use of the lithium metal anode in battery. Voltammetry and galvanostatic tests reveal significant enhancement of the electrolyte characteristics, in terms of cycling life and chemical stability, by the addition of lithium nitrate $\left(\mathrm{LiNO}_{3}\right)$ to the solution. Furthermore, PFG NMR measurements suggest the applicability of the electrolyte in battery in terms of ionic conductivity, lithium transference number, ionic-association degree and self-diffusion coefficient. Accordingly, the electrolyte is employed in a lithium battery using lithium iron phosphate as the selected cathode. The battery delivers a stable capacity of $150 \mathrm{mAh} \mathrm{g}^{-1}$ and flat working voltage of $3.5 \mathrm{~V}$, thus leading to a
\end{abstract}


theoretical energy density of $520 \mathrm{Wh} \mathrm{kg}^{-1}$. This battery is considered a suitable energy storage system for advanced applications requiring both high safety and high energy density.

\section{Introduction}

Lithium-based energy storage systems, studied since 1970s as primary battery and following within the rechargeable configuration, played crucial role in the recent development of the portable electronic technology [1]. In its most common design, a lithium battery employs a carbonate-based liquid electrolyte, a metal-oxide cathode in combination with a highly electropositive lithium metal anode, thus allowing a correspondingly high energy density [2]. However, the large scale deployment and acceptance of this powerful system has been hindered by safety issues associated with dendrite formation during cell charge, leading to internal short circuit, heat generation and flammability or, in rare cases, explosion [3]. This relevant inconvenient has been mitigated by the introduction of the lithium-ion battery, i.e., a system in which the lithium metal is replaced by a graphite intercalation anode [4]. However, this battery revealed a lower energy density with respect to lithium metal-based one, due to the higher working potential of graphite $(0.2 \mathrm{~V}$ instead of $0 \mathrm{~V}$ vs. $\left.\mathrm{Li} / \mathrm{Li}^{+}\right)$and to the lower specific capacity $\left(372 \mathrm{mAh} \mathrm{g}^{-1}\right.$ instead of $3800 \mathrm{mAh} \mathrm{g}^{-1}$, respectively). Recently, increased energy at the cathode side has been achieved by developing efficient lithiumsulfur [5-7] and the lithium-air [8-10] batteries. Indeed, the improvement of sulfur and oxygenbased electrodes, characterized by capacity largely exceeding the value associated with the common cathodes triggered renewed interest on the lithium metal anode [11,12]. Literature works demonstrated that the use of polymer electrolyte, such as PEO (polyethylene oxide), can allow a safe use of the lithium metal anode, however only at temperature exceeding $70^{\circ} \mathrm{C}[6,13-15]$. The addition of ceramics to the polymer electrolyte revealed increased performances in terms of conductivity and lithium transference number at the lower temperatures, however further improvements are still required in order to allow proper operation of these electrolytes at room temperature $[14,16]$. A valid alternative to solid PEO polymer, advantageously showing suitable 
room temperature conductivity and comparable safety content, is represented by highly viscose endcapped ethers, based on $\left(-\mathrm{OCH}_{2} \mathrm{CH}_{2}-\right)_{\mathrm{n}}$ groups of short chain configuration, such as polyethylene glycol dimethyl ether (PEG-DME) [17-19]. Despite their promise in terms of suitable characteristics for application in lithium ion battery [20-21], these ethers still suffer from issues related to the stability of lithium metal-electrolyte interphase, leading to resistance increase and cell polarization [22]. Several film-forming additives have been proposed to improve the anode interphase in organic electrolytes, such as vinylene carbonate (VC) [23] and fluoroethylene carbonate (FEC) [24]. However, these additives revealed suitable properties mainly in carbonatebased solvents. Among the various additives, lithium nitrate $\left(\mathrm{LiNO}_{3}\right)$ evidenced the most favorable effect in ether-based electrolyte, and, in particular, in cells using lithium metal anode [25-27]. The reductive decomposition of the $\mathrm{LiNO}_{3}$ at about $1.5 \mathrm{~V}$ vs. $\mathrm{Li} / \mathrm{Li}^{+}$may lead, in fact, to the formation of products migrating and precipitating at the lithium surface, thus protecting it from further side reactions [27].

In this paper we report a polyethylene glycol dimethyl ether (PEG, $500 \mathrm{MW}$ ) in a lithium metal cell using lithium iron phosphate $\left(\mathrm{LiFePO}_{4}\right)$ cathode. The electrolyte dissolves a lithium trifluoromethansulfonate $\left(\mathrm{LiCF}_{3} \mathrm{SO}_{3}\right)$ salt as lithium-ion conducting source, and an additional lithium nitrate $\left(\mathrm{LiNO}_{3}\right)$ salt acting as film forming agent at the lithium metal sulfate, thus allowing efficient behavior and low polarization of the lithium cell. Pulsed-field gradient (PFG) NMR and electrochemical measurements demonstrated the full compatibility of the electrolyte for the proposed application in terms of conductivity, lithium transport as well as stability against lithium metal.

\section{Experimental section}

Electrolyte and cathode preparation 
Polyethylene glycol dimethyl ether (Sigma Aldrich, average MW 500, following indicated

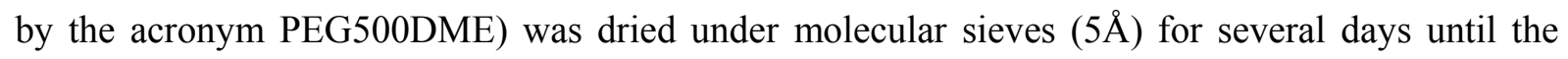
water content was under $10 \mathrm{ppm}$ as determined by Karl Fischer titration instrument (Metrohm). Lithium-trifluoromethanesulfonate $\left(\mathrm{LiCF}_{3} \mathrm{SO}_{3}\right.$, Sigma Aldrich) and lithium nitrate $\left(\mathrm{LiNO}_{3}\right.$, Sigma Aldrich) were dried at $100^{\circ} \mathrm{C}$ under vacuum for 24 hours. The electrolyte solution was prepared by dissolving $1 \mathrm{~mol}$ of $\mathrm{LiCF}_{3} \mathrm{SO}_{3}$ in $1 \mathrm{~kg}$ of PEG500DME. A second solution of the same composition as the previous, with 0.4 mol of $\mathrm{LiNO}_{3}$ added was also prepared. The cathode film was prepared by doctor blade casting of a homogeneous slurry formed by dispersing $\mathrm{LiFePO}_{4}$ [21], super $\mathrm{P}$ carbon conductor (Timcal) and polyvinylidinedifluoride (PVDF, Solvay) binder in 80:10:10 mass ratio in N-methylpirrolidone (NMP, Aldrich). The cathode film was cast onto aluminum foil with wet thickness of $300 \mu \mathrm{m}$, dried under air at $70^{\circ} \mathrm{C}$, disk-punched and finally dried under vacuum at $100^{\circ} \mathrm{C}$ for 3 hours to remove solvent and moisture traces.

\section{Materials characterization}

Self-diffusion coefficient (D) was measured with a Bruker 400 Avance III NMR spectrometer and using a PFG double-stimulated echo sequence in order to suppress convection effects [28]. The measurements were performed within temperature ranging from $20^{\circ} \mathrm{C}$ to $70^{\circ} \mathrm{C}$, collecting the signal each $10{ }^{\circ} \mathrm{C}$. Gradient pulses with duration $=4-5 \mathrm{~ms}$ and strength $\mathrm{g}=0-45$ $\mathrm{G} / \mathrm{cm}$, and diffusion delay of $\Delta=500-800 \mathrm{~ms}$ were used. The electrolyte conductivity $(\delta)$ was calculated by using the diffusion coefficient of the anion and the cation along with the NernstEinstein equation (1):

$$
\delta=\frac{\mathrm{F}^{2}[\mathrm{C}]}{\mathrm{RT}}\left(\mathrm{D}_{\mathrm{Li}}+\mathrm{D}_{\mathrm{CF}_{3} \mathrm{SO}_{3}}\right)
$$

where $\mathrm{F}$ is the Faraday constant (96485 Coulomb), [C] is the solution concentration ( $\left.\mathrm{mol} \mathrm{cm} \mathrm{c}^{-3}\right), \mathrm{R}$ is the ideal-gas constant $\left(8.314472 \mathrm{~J} \mathrm{~K}^{-1} \mathrm{~mol}^{-1}\right)$, $\mathrm{T}$ is the selected temperature value, $\mathrm{D}_{\mathrm{Li}}$ and $\mathrm{D}_{\mathrm{CF} 3 \mathrm{SO}_{3}}$ are the self-diffusion coefficients of the $\mathrm{Li}^{+}$cation and $\mathrm{CF}_{3} \mathrm{SO}_{3}{ }^{-}$anion, respectively, measured by 
NMR. The ionic conductivity was also directly determined within temperature ranging from $20^{\circ} \mathrm{C}$ to $90^{\circ} \mathrm{C}$ by electrochemical impedance spectroscopy (EIS) in symmetric stainless steel/electrolyte/stainless steel 2032 coin cell. The cell was equipped with a Teflon separator in order to fix the cell thickness, and the impedance spectroscopy was performed in a $100 \mathrm{mHz}-100$ $\mathrm{kHz}$ frequency range with a signal amplitude of $10 \mathrm{mV}$ using Biological VMP3 instrument.

The ion association degree $(\alpha)$ was determined by using equation (2):

$\alpha=\left(1-\frac{\delta_{E I S}}{\delta_{N M R}}\right)$

where $\delta_{\mathrm{EIS}}$ and $\delta_{\mathrm{NMR}}$ are the conductivity measured by EIS and calculated by equation (1), respectively.

The cation transference number $\left(\mathrm{t}^{+}\right)$, corresponding to the fraction of current carried out by the lithium ions, was calculated by using equation (3):

$t^{+}=\frac{D_{L i}}{D_{L i}+D_{C F_{3} S O_{3}}}$

Cyclic voltammetry was carried out by using a three-electrodes cell with lithium metal counter and reference electrodes and a Super P coated on copper working electrode. The measurement was performed with a $10 \mathrm{mV} \mathrm{s}^{-1}$ scan rate, within $0.01 \mathrm{~V}$ and $3 \mathrm{~V}$ potential window using a Biological VMP3 instrument. Swagelok, T-type lithium cells using lithium iron phosphate $\left(\mathrm{LiFePO}_{4}\right)$ cathode and PEG500DME-based electrolyte soaked in a Whatman ${ }^{\circledR}$ glass fiber separator, were galvanostatically characterized at $\mathrm{C} / 5$ rate $\left(1 \mathrm{C}=170 \mathrm{~mA} \mathrm{~g}{ }^{-1}\right)$ using a MACCOR Series 4000 Battery Test System (Maccor Inc.).

\section{Results and discussion}


The suitability of the PEG500DME- $\mathrm{LiCF}_{3} \mathrm{SO}_{3}$ electrolyte in terms of ion mobility for application in battery has been verified both by PFG NMR and by electrochemical method. Figure 1(a) reports the self-diffusion coefficient (D) of ${ }^{7} \mathrm{Li},{ }^{19} \mathrm{~F}$ and ${ }^{1} \mathrm{H}$ within the electrolyte, as obtained by NMR measurement (the ${ }^{1} \mathrm{H}$ NMR results will not be discussed further here, but they are mostly reflective of solution viscosity). The figure evidences that lithium, i.e. the smallest particle in the solution, is characterized by the lowest values of diffusion coefficient due to a high solvation degree in view of its high charge density. Furthermore, the figure reveals the expected increase of the diffusion coefficient of the various species by increasing the temperature. The diffusion coefficient of the cation $\left(\mathrm{D}_{\mathrm{Li}}\right)$ and of the anion $\left(\mathrm{D}_{\mathrm{CF}_{3} \mathrm{SO}_{3}}\right)$ at the various temperatures, represented by $\mathrm{D}_{\mathrm{Li}}$ $\left(\mathrm{LiCF}_{3} \mathrm{SO}_{3}\right)$ and $\mathrm{D}_{\mathrm{F}}\left(\mathrm{LiCF}_{3} \mathrm{SO}_{3}\right)$ in Figure 1a, respectively, are used to determine the electrolyte ionic conductivity following the Nernst-Einstein formula, see equation (1) in the experimental section. Figure $1 \mathrm{~b}$ reports the comparison between the conductivity values determined by NMR and directly measured by electrochemical impedance spectroscopy (EIS). The figure reveals a conductivity at $30^{\circ} \mathrm{C}$ of nearly $10^{-3} \mathrm{~S} \mathrm{~cm}^{-1}$, i.e., a satisfactory value suitable for battery application. However, the plots reveal a discrepancy between the value directly measured by EIS and that determined by employing the diffusion coefficient, i.e., the latter higher in respect to the former. Indeed, PFG NMR reveals the movement of all the species within the electrolyte solution, including single ions, neutral ionic pairs, couples and multiple associated ions. On the other hand, impedance spectroscopy records only the movement ascribed to the single charge carriers. This is a wellknown and widely reported phenomena in both liquid and PEO-based solid electrolytes [29,30]. Accordingly, the ratio between the two values may be employed to determine the ionic association degree $(\alpha)$ using equation (2) reported in the experimental section. Figure 1(c), reporting the trend of $\alpha$, reveals an increase of the ionic association by increasing the temperature as most likely ascribed to possible recombination of the various ions into couples pairs or higher multiplet. This effect is in part due to the decreasing dielectric constant and hence decreasing solvating power of the polyether host at elevated temperature [31]. Li-transference number has been determined by 
NMR at the various temperatures and reported in Figure 1(d), in order to evaluate the charge fraction carried by lithium ions. The figure shows a stable value of about 0.45 in the whole temperature range that is considered a suitably high value allowing the use of the electrolyte in lithium ion batteries.

\section{Figure 1}

In order to verify the suitability of the electrolyte for lithium battery application, a $\mathrm{Li} / \mathrm{PEG} 500 \mathrm{DME}-1 \mathrm{M} \mathrm{LiCF} 3 \mathrm{SO}_{3} / \mathrm{LiFePO}_{4}$ cell was assembled and cycled. Figure 2, reporting the voltage profile (a) and corresponding cycling behavior (b), reveals an initial cycle characterized by a typical profile centered at about $3.5 \mathrm{~V}$, a low charge-discharge polarization, a high efficiency and a specific capacity of about $150 \mathrm{mAh} \mathrm{g}^{-1}$, i.e., of about $90 \%$ of the theoretical value. However, the following cycles evidence a remarkable polarization increase (Fig.2a) leading to efficiency decrease, noise, capacity fading and final cell failure (Fig.2b). These issues are attributed to an unstable solid electrolyte interphase (SEI) film at the lithium surface, or to a very poor stability of the latter.

Figure 2

It has been reported that the addition of lithium nitrate $\left(\mathrm{LiNiO}_{3}\right)$ to the electrolyte as filmforming agent may represent a suitable solution to increase the lithium cell performance [25-27]. Indeed, $\mathrm{LiNiO}_{3}$ may decompose at about $1.5 \mathrm{~V}$ to form a stable $\mathrm{SEI}$ layer protecting the lithium surface and preventing cell degradation. Accordingly, PEG500DME- $\mathrm{LiCF}_{3} \mathrm{SO}_{3}$ solution has been augmented by the addition of $\mathrm{LiNO}_{3}$ salt and characterized by voltammetry in order to detect its decomposition potential. Figure 3 reports the cyclic voltammetry of the bare PEG500DME-based electrolyte (dark gray line) and the corresponding solution containing $\mathrm{LiNO}_{3}$ (light green line) in a lithium cell using a carbon working electrode. The potential profiles show a huge peak around $0.5 \mathrm{~V}$ mainly due to the reductive degradation of the PEG500DME for the bare electrolyte, and the expected additional peak at around $1.5 \mathrm{~V}$ for the $\mathrm{LiNO}_{3}$ containing one that is expected to form the 
above mentioned protective layer [25-27]. Following the first scan, both the curves show vanishing signals, thus indicating consolidation and consequent stabilization of the formed SEI film upon the repeated cycles that is a crucial requirement for electrolyte suitability in lithium battery.

Figure 3

The voltammetry test suggests a discharge voltage lower than $1.5 \mathrm{~V}$ in order to allow $\mathrm{LiNO}_{3}$ decomposition with production of a passivation film preventing cell deterioration. Accordingly, we assembled a Li/PEG500DME, $1 \mathrm{M} \mathrm{LiCF} 3 \mathrm{SO}_{3}, 0.4 \mathrm{M} \mathrm{LiNO} / \mathrm{LiFePO}_{4}$ cell and performed a first discharge lowering the voltage down to $1 \mathrm{~V}$ in order to allow the $\mathrm{LiNO}_{3}$ decomposition, while the following cycles were performed within a typical voltage range, i.e. $2.5 \mathrm{~V}$ to $4 \mathrm{~V}$. Figure 4 , reporting the voltage profiles (a) and the cycling behavior (b) of the lithium cell, shows a greatly enhanced behavior in terms of low polarization and cycling stability. During the first cycle the cell reveals the expected decomposition starting at about $1.5 \mathrm{~V}$ and a following charge characterized by a specific capacity of about $170 \mathrm{mAh} \mathrm{g}^{-1}$, comprised of irreversible reactions such as minor electrolyte oxidation and structural reorganization of the $\mathrm{LiFePO}_{4}$ electrode [21]. During the following cycles, the cell reveals a working voltage of about $3.5 \mathrm{~V}$, very limited polarization and a specific capacity of about $150 \mathrm{mAh} \mathrm{g}^{-1}$ that is $90 \%$ of the theoretical value (Fig. 4a). Furthermore, the cell shows an efficiency approaching $100 \%$ and a very stable cycling trend (Fig. 4b), thus confirming the effective role of the film formed by $\mathrm{LiNO}_{3}$ in protecting the cell from side reactions and allowing optimized cycling.

Figure 4

\section{Conclusion}

The results here reported demonstrated the suitability of a polyethylene glycol dimethyl ether (PEGDME)-based electrolyte for application in an efficient lithium battery. NMR and electrochemical tests revealed that the electrolyte has a conductivity of the order of $10^{-3} \mathrm{~S} \mathrm{~cm}^{-1}$ and 
a lithium transference number of 0.45 , i.e. proper values for optimized cell performances. The addition of a lithium nitrate salt $\left(\mathrm{LiNO}_{3}\right)$ allowed the formation of a stable SEI film protecting the lithium metal and avoiding further electrolyte decomposition. Indeed, the lithium battery employing the modified electrolyte has shown high performances in terms of delivered capacity, efficiency and stability. The cell delivered a capacity of $150 \mathrm{mAh} \mathrm{g}^{-1}$ at a working voltage of $3.5 \mathrm{~V}$, thus leading to a theoretical energy density of $525 \mathrm{Wh} \mathrm{kg}^{-1}$. We believe that the data here reported may allow a safe use of lithium metal in efficient, high energy lithium batteries.

\section{Acknowledgments}

The work at Hunter College was supported by a grant from the U.S. Office of Naval Research, and the Hunter NMR facility is funded by a National Institutes of Health RCMI infrastructure grant (RR 003037).

\section{References}

[1] B. Scrosati, J. Garche, J.Power Sources 195 (2010) 2419-2430

[2] J. M. Tarascon, M. Armand, Nature 414 (2001) 359-367

[3] Q. Wang, P. Ping, X. Zhao, G. Chu, J. Sun and C. Chen, J. Power Sources 2012, 208, 210-224

[4] M. Lazzari and B. Scrosati, J. electrochemical Society 1980, 127, 773-774

[5] M. Agostini and J. Hassoun, Scientific Reports 2015, 5, 7591

[6] J. Kim, D. J. Lee, H. G. Jung, Y. K. Sun, J. Hassoun and B. Scrosati, Advanced Functional Materials, 2013, 23, 1076-1080

[7] L. Suo, Y. S. Hu, H. Li, M. Armand and L. Chen, Nature communications, 2013, 4, 1481.

[8] H.G. Jung, J. Hassoun, J.B. Park, Y.K. Sun and B. Scrosati, Nature Chemistry, 2012, 4, 579-585 
[9] B. M. Gallant, D. G. Kwabi, R. R. Mitchell, J. Zhou, C. V. Thompson and Y. ShaoHorn, Energy \& Environmental Science, 2013, 6 , 2518-2528.

[10] C. Laoire, S. Mukerjee, E. J. Plichta, M. A. Hendrickson and K. M. Abraham, J. Electrochemical Society, 2011,158, A302-A308.

[11] G. Zheng, S. W. Lee, Z. Liang, H. W. Lee, K. Yan, H. Yao and Y. Cui, Nature nanotechnology, 2014, 9, 618-623.

[12] W. Xu, J. Wang, F. Ding, X. Chen, E. Nasybulin, Y. Zhang and J.G. Zhang, RSC advances $2014,7,513-537$

[13] S. Rajendran, T. Mahalingam and R. Kannan, Solid State Ionics 2000, 130, 143-148

[14] F. Croce, G. B. Appetecchi, L. Persi and B. Scrosati, Nature 1998, 394, 456-458

[15] M. Balaish, E. Peled, D. Golodnitsky and Y. Ein-Eli, Angewandte Chemie International Edition, 2015, 54, 436-440.

[16] F. Croce, R. Curini, A. Martinelli, L. Persi, F. Ronci and B. Scrosati, J. Phys. Chem. 1999, $103,10632-10638$

[17] G. A. Elia, R. Bernhard and J. Hassoun, RSC Advances, 2015, 5, 21360-21365.

[18] D. Marmorstein, T.H. Yu, K.A. Striebel, F.R. McLarnon, J. Hou and E.J. Cairns, J. Power Sources 2000, 89, 219-226

[19] D. Devaux, R. Bouchet, D. Glé and R. Denoyel, Solid State Ionics, 2012, 227, 119-127.

[20] R. Bernhard, A. Latini, S. Panero, B. Scrosati and J. Hassoun, J. Power Sources, 2013, 226, 329-333.

[21] D. J Lee, J. Hassoun, S. Panero, Y. K. Sun and B. Scrosati, Electrochemistry Communications, 2012, 14, 43-46.

[22] S. S. Zhang, J. Power Sources, 2013, 231, 153-162. 
[23] D. Aurbach, K. Gamolsky, B. Markovsky, Y. Gofer, M. Schmidt and U. Heider, Electrochimica Acta, 2002, 47, 1423-1439.

[24] R. Elazari, G. Salitra, G. Gershinsky, A. Garsuch, A. Panchenko and D. Aurbach J. Electrochemical Society, 2012, 159, A1440-A1445.

[25] C. Barchasz, J. C. Leprêtre, S. Patoux and F. Alloin, J. Electrochemical Society, 2013, 160, A430-A436.

[26] S. Xiong, K. Xie, Y. Diao, and X. Hong, Electrochimica Acta, 2012, 83, 78-86.

[27] A. Rosenman, R. Elazari, G. Salitra, E. Markevich, D. Aurbach, and A. Garsuch, J. Electrochemical Society, 2015, 162, A470-A473.

[28] A. Jerschow and N. Müller, J. Magnetic Resonance 1997, 125, 372-375

[29] X. Bogle, R. Vazquez, S. G. Greenbaum, A. V. W. Cresce and K. Xu, The Journal of Physical Chemistry Letters, 2013, 4, 1664-1668.

[30] S. Abbrent and S. G. Greenbaum, Current Opinion in Colloid and Interface Science, 2013, 18, 228-244.

[31] M.C. Wintersgill, J.J. Fontanella, M.K. Smith, Y.S. Pak, C.G. Andeen, and S.G. Greenbaum, Journal of the Electrochemical Society, 1988, 34, 135-235.

\section{Figures caption}

Figure 1. a) Self-diffusion coefficient (D) of ${ }^{7} \mathrm{Li},{ }^{19} \mathrm{~F}$ and ${ }^{1} \mathrm{H}$ within the PEG500DME-LiCF $\mathrm{SO}_{3}$ electrolyte determined by PFG NMR. b) Comparison between the conductivity values determined using self-diffusion coefficients (equation 1) and directly measured by electrochemical impedance spectroscopy (EIS). c) Ionic association degree $(\alpha)$ trend determined at various temperatures using self-diffusion coefficients (equation 2). d) Lithium transference number $\left(\mathrm{t}^{+}\right)$trend determined at various temperatures (using equation 3). Temperature range $20^{\circ} \mathrm{C}-90^{\circ} \mathrm{C}$. For equations (1), (2) and (3) see experimental section. 
Figure 2. a) Voltage profiles and b) cycling behavior of the Li/PEG500DME, 1M $\mathrm{LiCF}_{3} \mathrm{SO}_{3} / \mathrm{LiFePO}_{4}$ lithium cell cycled at a $\mathrm{C} / 5$ rate $\left(1 \mathrm{C}=170 \mathrm{mAh} \mathrm{g} \mathrm{g}^{-1}\right)$ within $2.5 \mathrm{~V}$ and $4 \mathrm{~V}$ voltage range. Room temperature $\left(25^{\circ} \mathrm{C}\right)$

Figure 3. Cyclic voltammetry trends of the bare PEG500DME, $1 \mathrm{M} \mathrm{LiCF} 3 \mathrm{SO}_{3}$ electrolyte (Dark gray line) and the corresponding solution added by $0.4 \mathrm{M} \mathrm{LiNO}_{3}$ (light green line) in a lithium cell using a carbon working electrode. Scan rate $0.1 \mathrm{mV} \mathrm{s}^{-1}$, potential limits $0.01 \mathrm{~V}-2 \mathrm{~V}$. Room temperature $\left(25^{\circ} \mathrm{C}\right)$

Figure 4. a) Voltage profiles and b) cycling behavior of the Li/PEG500DME, $1 \mathrm{M} \mathrm{LiCF} 3 \mathrm{SO}_{3}, 0.4 \mathrm{M}$ $\mathrm{LiNO}_{3} / \mathrm{LiFePO}_{4}$ lithium cell cycled at a $\mathrm{C} / 5$ rate $\left(1 \mathrm{C}=170 \mathrm{mAh} \mathrm{g}{ }^{-1}\right)$. First cycle performed within $1 \mathrm{~V}$ and $4 \mathrm{~V}$ and following cycles within $2.5 \mathrm{~V}$ and $4 \mathrm{~V}$ voltage range. Room temperature $\left(25^{\circ} \mathrm{C}\right)$ 


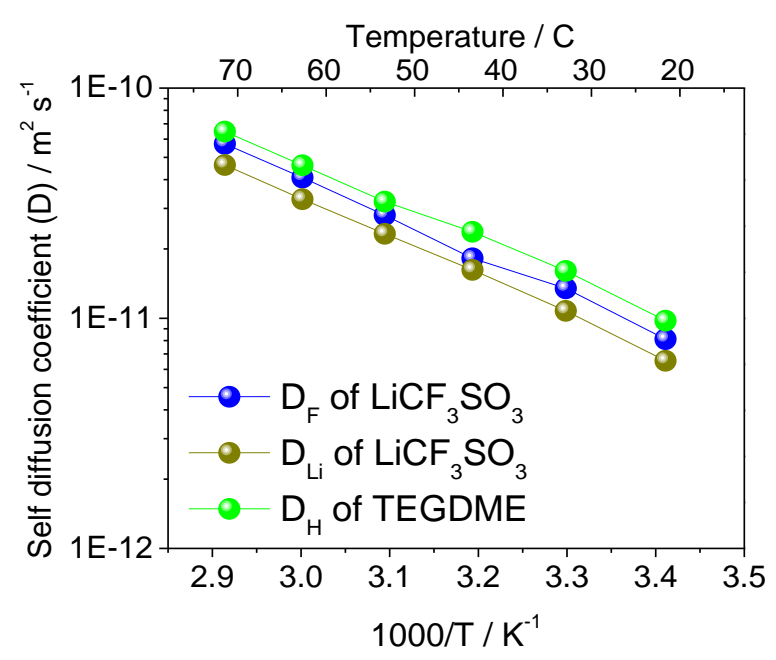

(a)

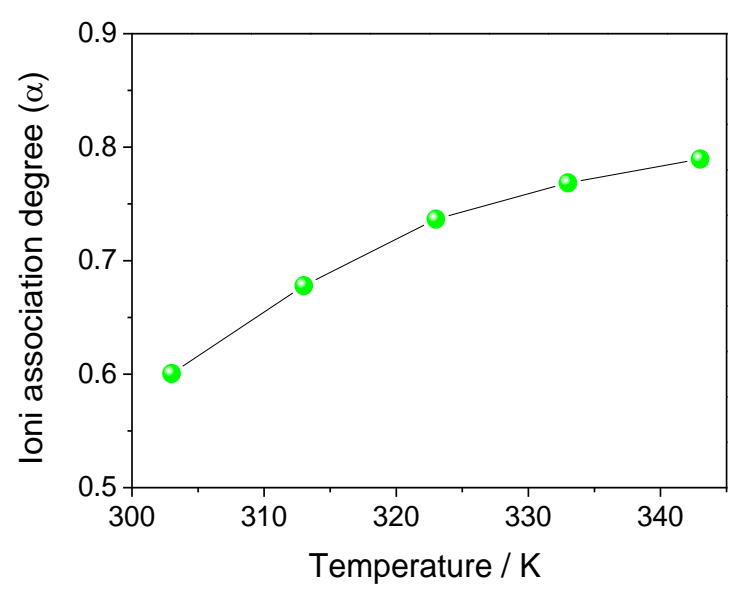

(c)
Temperature $/{ }^{\circ} \mathrm{C}$

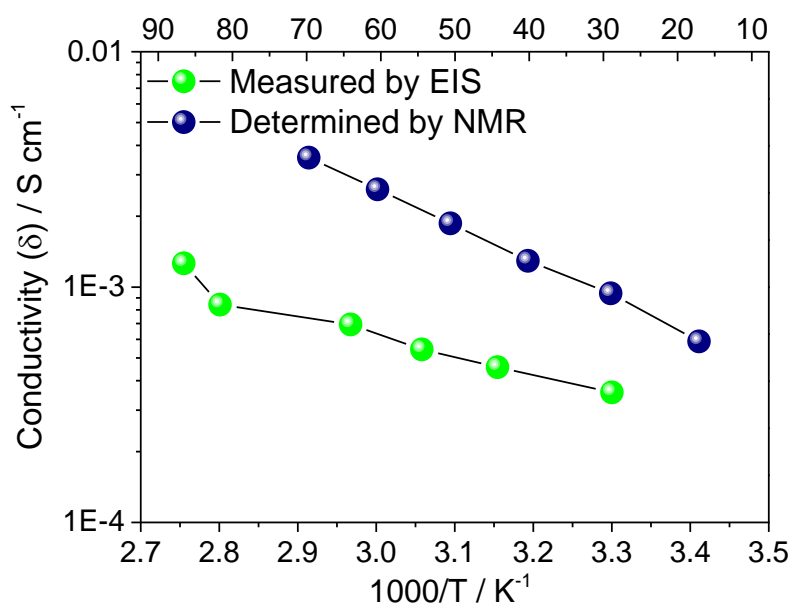

(b)

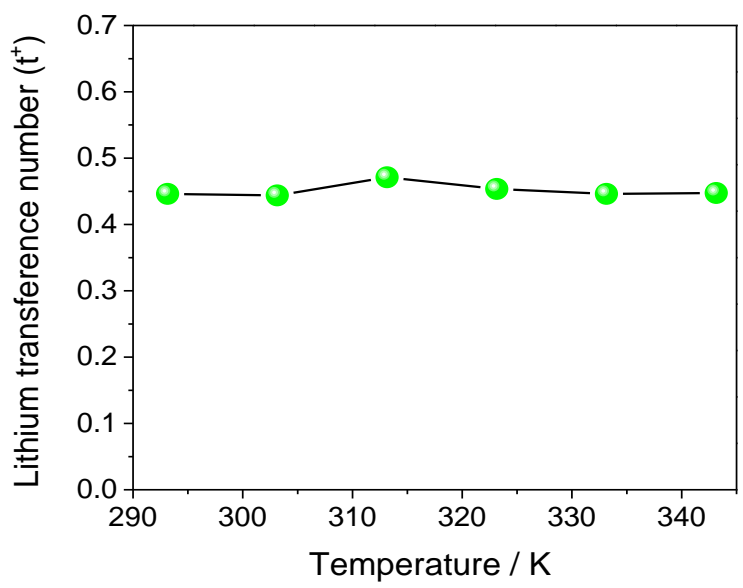

(d)

Figure 1 


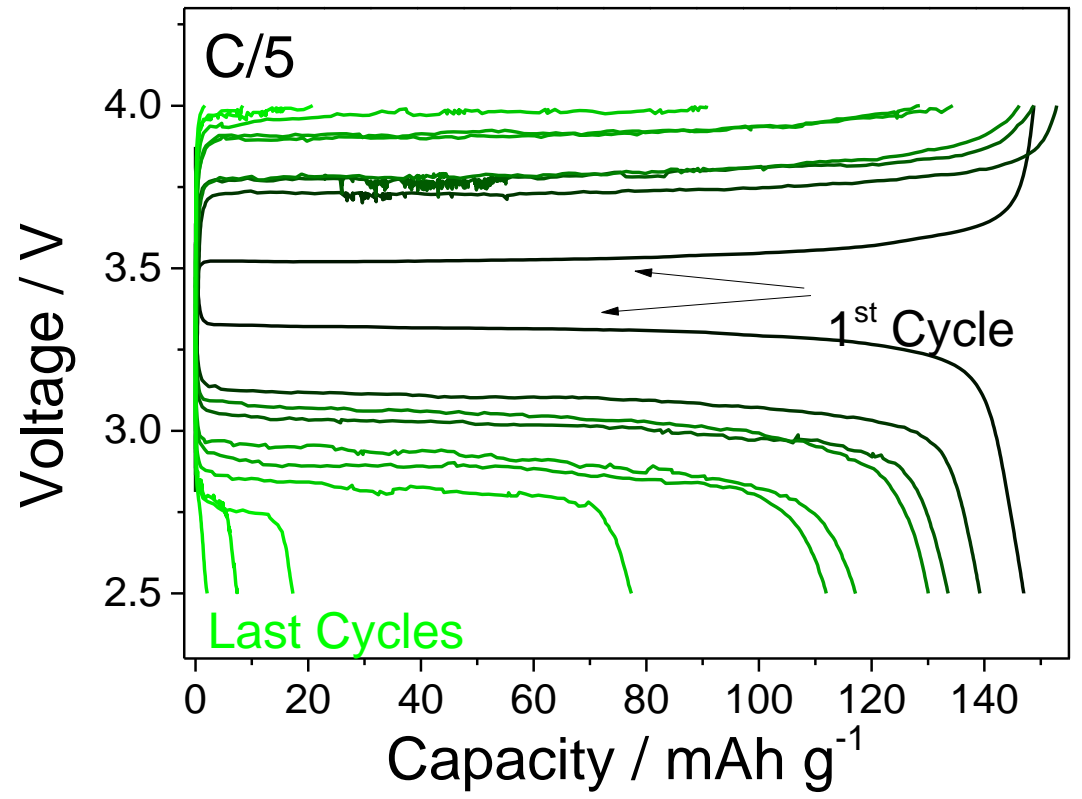

(a)

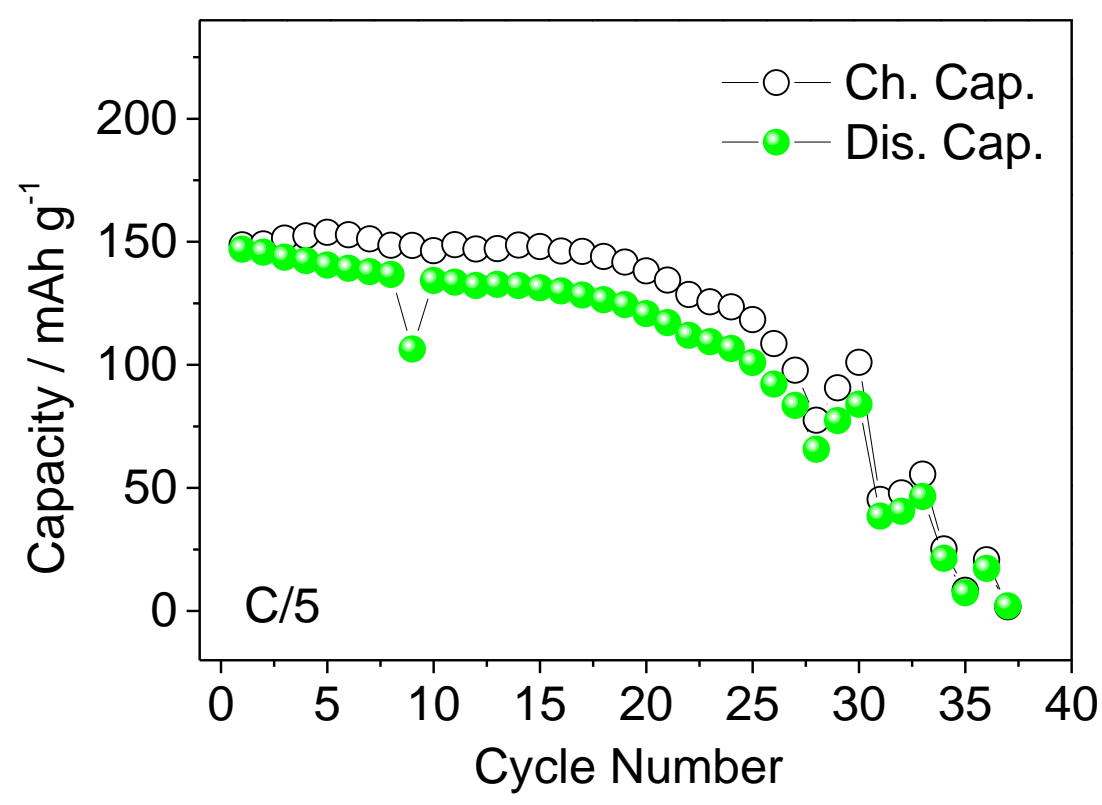

(b)

Figure 2 


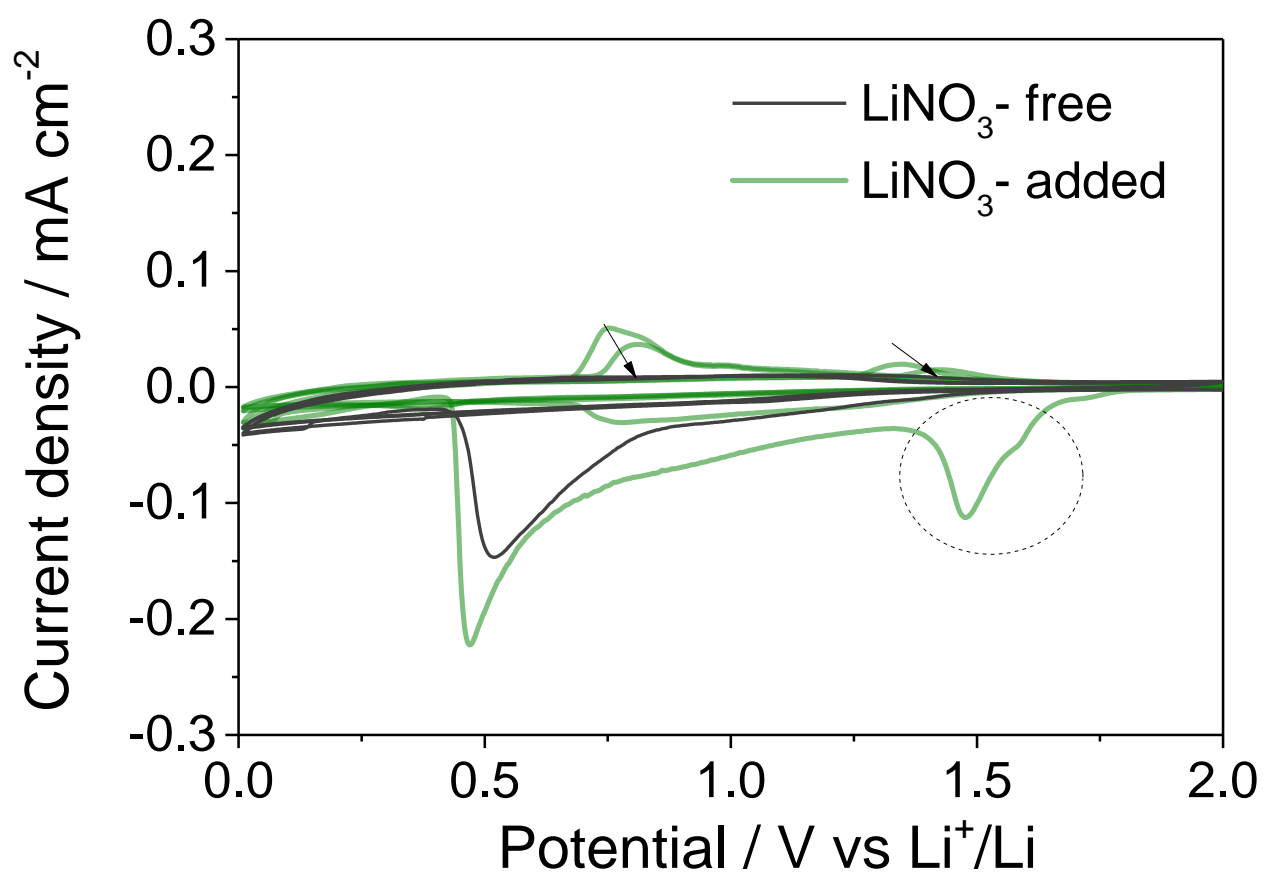

Figure 3 


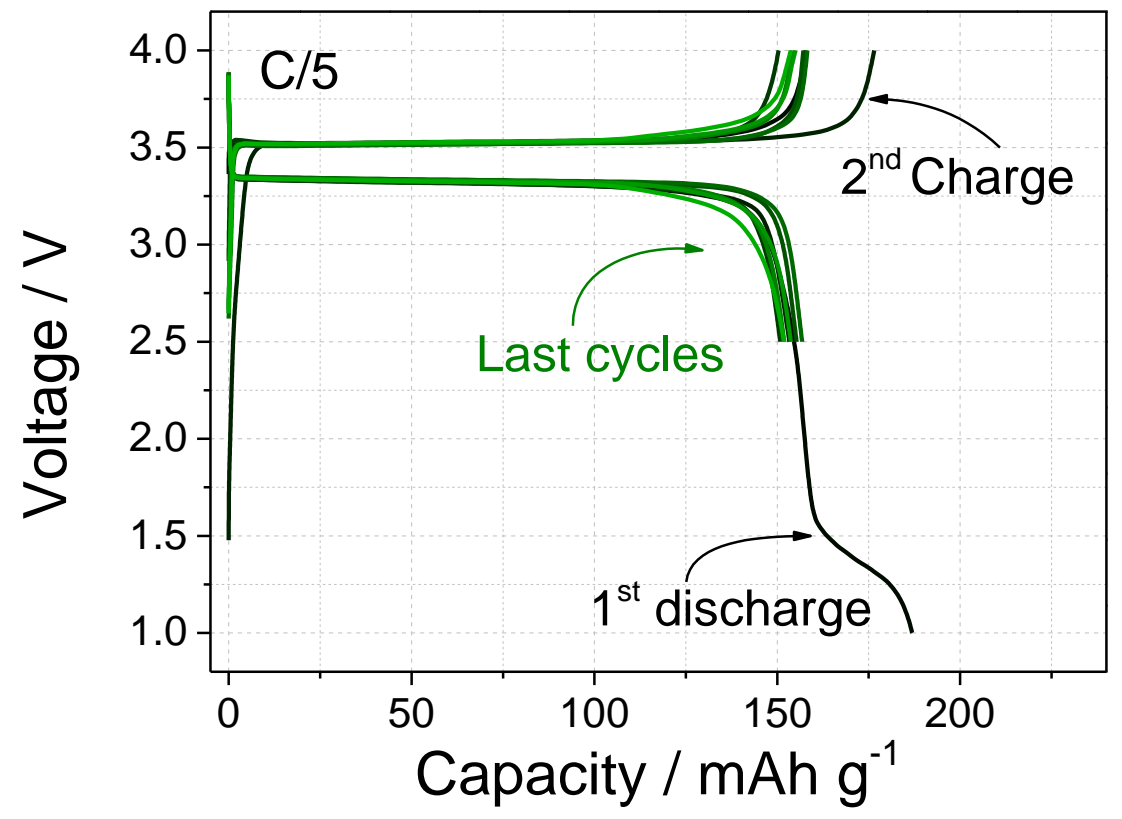

(a)

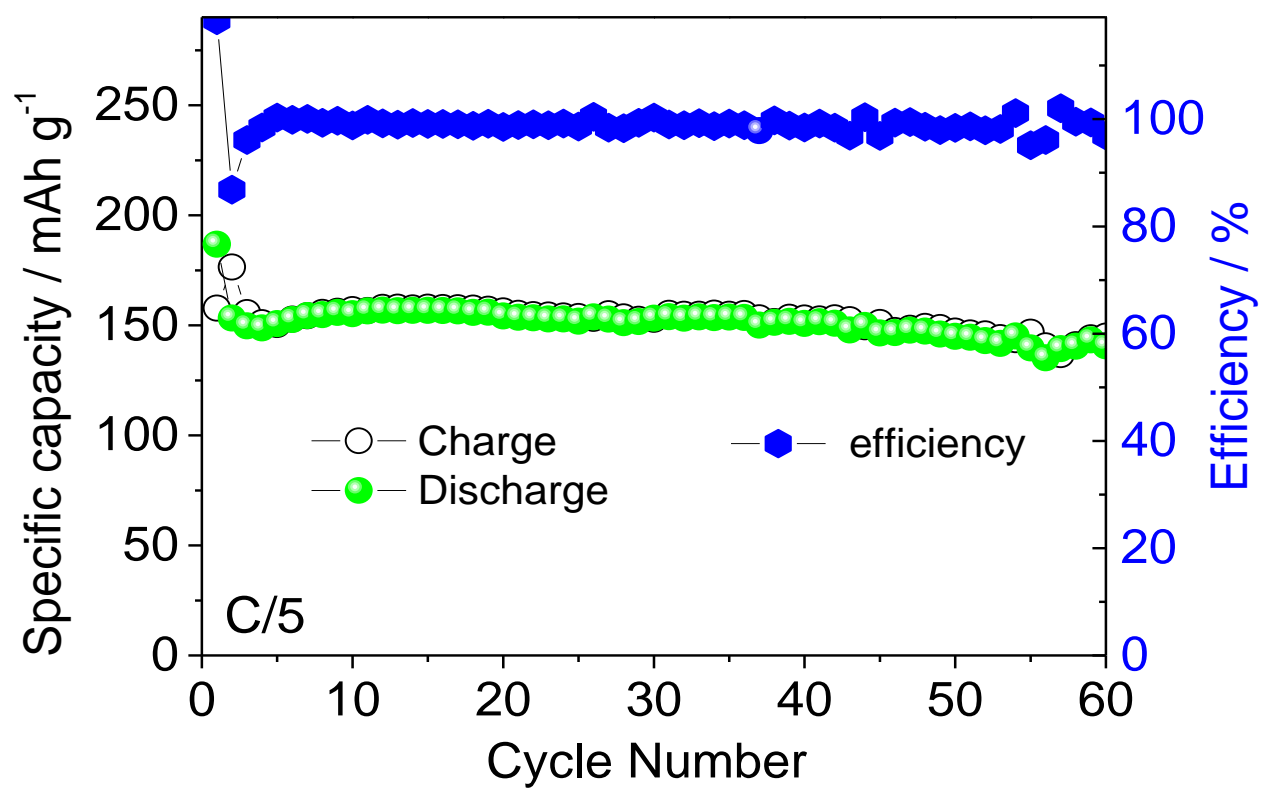

(b)

Figure 4 
Graphical Abstract

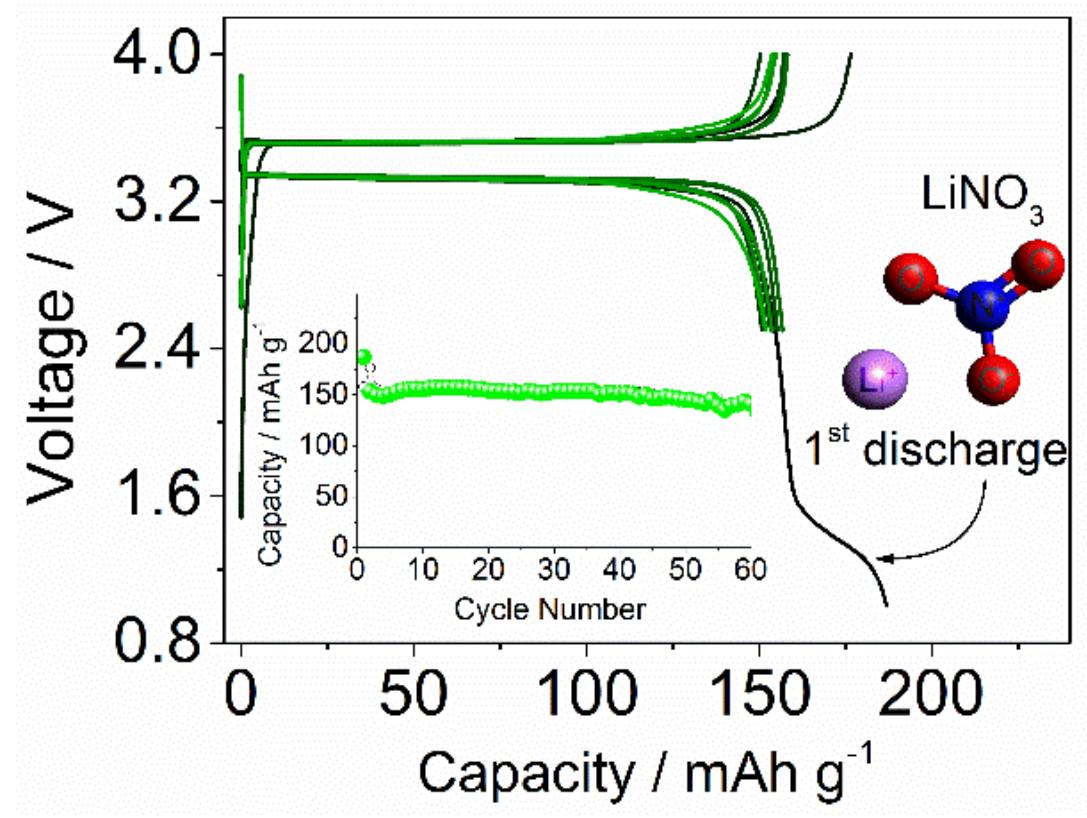

